\title{
DESENVOLVIMENTO DE MICROCÉLULA ELETROQUÍMICA PARA ESTUDOS DE MICRORREGIÕES
}

\author{
Adriano Heleno Akita, José Tiago Claudino Barragan, Cecílio Sadao Fugivara e Assis Vicente Benedetti* \\ Departamento de Físico-Química, Instituto de Química, Universidade Estadual Paulista Julio Mesquita Filho, CP 355, 14801-970 \\ Araraquara - SP, Brasil
}

Recebido em 25/4/11; aceito em 9/6/11; publicado na web em 5/8/11

\begin{abstract}
DEVELOPMENT OF AN ELECTROCHEMICAL MICROCELL FOR STUDIES OF MICRO REGIONS. The construction and optimization of a device that can be applied to electrochemical studies in flat micro regions are described. This was developed as an attempt to study small regions of metallic samples, whose properties may differ completely from its macroscopic behavior and for studies in highly resistive medium. Some results were obtained for individual grains of polycrystalline samples, welded regions, pure copper, platinum, glassy carbon, single crystals of $\mathrm{Cu}-\mathrm{Zn}-\mathrm{Al}$ alloy, and steel in biodiesel without electrolyte intentionally added. The device showed to be useful for the proposed purpose, allowing to be automated and has potential possibilities of other applications.
\end{abstract}

Keywords: electrochemical microcell; scanning droplet cell; localized electrochemical analysis.

\section{INTRODUÇÃO}

Diferentemente dos eletrodos líquidos como, por exemplo, os eletrodos de mercúrio, a maioria dos estudos eletroquímicos em amostras metálicas monofásicas exibe resultados que representam uma média ponderada das contribuições de vários planos cristalinos e defeitos expostos ao eletrólito. Esses estudos se tornam ainda mais complexos e de difícil reprodutibilidade em sistemas com mais de uma fase. ${ }^{1}$

Uma alternativa escolhida por nosso grupo para obter resultados mais significativos de ligas metálicas e de metais não nobres foi a realização de estudos em monocristais orientados. ${ }^{2,3}$ No entanto, a obtenção de monocristais orientados geralmente demanda tempo, exige equipamentos específicos além de conhecimentos e habilidades do operador. Somado a isso, alguns materiais são difíceis de obter corpos monocristalinos por meio de técnicas convencionais. ${ }^{2}$

Em meados do segundo semestre de 2005, uma alternativa encontrada por nosso grupo foi a construção de células eletroquímicas que permitem estudos em escala micro e que resultou numa dissertação de mestrado. ${ }^{4}$ Essa escala geralmente é da ordem do tamanho dos grãos que compõem alguns materiais metálicos policristalinos, podendo ter tamanho ao redor de $200 \mu \mathrm{m}$ de diâmetro. ${ }^{4}$ Acredita-se que o interior da superfície de um único grão se comporta como um corpo monocristalino já que quase sempre apresentam regularidades de longo alcance no arranjo atômico. As técnicas de difração de raios-X por retro-reflexão de Laüe $^{5}$ ou difração de elétrons retroespalhados $(\text { EBSD })^{6}$ são geralmente as mais utilizadas para determinação da orientação cristalográfica de grãos individuais. Assim, por meio da utilização de uma microcélula com uma única amostra policristalina é possível avaliar uma grande quantidade de monocristais com diferentes orientações. ${ }^{7}$

Ao longo dos últimos 10 anos verificou-se um aumento significativo no número de publicações sobre o tema, deixando cada vez mais evidente a potencialidade de aplicação da microcélula não só a estudos de grãos, ${ }^{7-9}$ mas também em contornos de grão, fases, ${ }^{10}$ filmes de óxidos, ${ }^{11}$ investigação de defeitos de revestimentos de $\mathrm{CrNx}$ sobre ligas de magnésio, ${ }^{12}$ regiões de solda, ${ }^{13}$ micropartículas, ${ }^{14}$ semicondutores, ${ }^{15}$ eletrodissolução, ${ }^{16,17}$ filmes finos e ultrafinos, ${ }^{18}$ estudo de inclusões e de um único pite de corrosão, ${ }^{19}$ precipitados e produtos de reações em estado sólido, ${ }^{20}$ regiões passivadas, ${ }^{7,21}$ eletrodeposição, ${ }^{22}$ e outros.

\footnotetext{
*e-mail: benedeti@iq.unesp.br
}

Somente em meados do segundo semestre de 2008 foi divulgado talvez o primeiro equipamento comercial destinado a esse tipo de medida de Tomas Suter.

A microcélula também pode ser utilizada com todas as técnicas eletroquímicas como voltametria cíclica, curvas de polarização, medidas de potencial de circuito aberto, cronoamperometria, cronopotenciometria, técnicas eletroanalíticas pulsadas e espectroscopia de impedância eletroquímica além da análise por meio de eletrodos íon-seletivos. Uma técnica que merece destaque é a técnica de espectroscopia de impedância eletroquímica, uma das mais poderosas técnicas para caracterização de sistemas eletroquímicos ${ }^{23}$ e seu poder foi ampliado com a utilização conjunta da microcélula. Essa sinergia possibilitou caracterizar materiais com resolução espacial por medidas passo a passo. ${ }^{12,24}$

Com o desenvolvimento adequado da ponteira também é possível acoplar sistemas em fluxo como espectroscopia UV/VIS, cromatografia líquida, eletroforese capilar, polarografia e outras. Esse desenvolvimento permite obter informações complementares como a realização de análise imediata de produtos de reações eletroquímicas. ${ }^{25}$

Neste trabalho buscou-se descrever a montagem de uma microcélula eletroquímica, sua evolução em nosso laboratório e alguns resultados obtidos em pequenas regiões de amostras metálicas.

\section{PARTE EXPERIMENTAL}

\section{Confecção da microcélula eletroquímica}

Para medidas eletroquímicas em escala micro foi desenvolvida uma microcélula ou uma célula baseada em um microcapilar. Os principais componentes da microcélula são enumerados na Figura 1: 1) seringa para injeção de eletrólito e controle do menisco na extremidade da microcélula; 2) cânula que conecta a seringa ao corpo da microcélula; 3 ) minieletrodo de referência de $\mathrm{Ag}|\mathrm{AgCl}| \mathrm{Cl}^{-} 3$ mol $\mathrm{L}^{-1}\left(0,197 \mathrm{~V} / \mathrm{SHE}\right.$ a $\left.25^{\circ} \mathrm{C}\right)$ confeccionado em vidro alcalino e com ponteira de Ti/óxido de Ti que permite o contato iônico; 4) eletrodo auxiliar formado por um fio fino de platina (200 $\mu \mathrm{m}$ de diâmetro) colocado na forma de espiral no interior da microcélula; 5) placa de aço inoxidável de $3 \times 4 \mathrm{~cm}$ utilizada como suporte e contato elétrico para o eletrodo de trabalho; 6) microcélula propriamente dita confeccionada em vidro Pyrex ${ }^{\circledR}$ com capacidade total para $1 \mathrm{~mL}$ de eletrólito após a montagem; 7) corpo da microcélula confeccionado 
em Teflon $\left.{ }^{\circledR} ; 8\right)$ rosca usinada e confeccionada em latão revestido com Ni químico (electroless), utilizada para conectar o corpo da microcélula ao microscópio óptico em lugar de uma das lentes objetiva. Os conectores foram confeccionados em Nylon ${ }^{\circledR}$; O-rings foram colocados no corpo dos conectores com a função de vedar e fixar os componentes ao corpo da microcélula e deste à microcélula propriamente dita. A vedação na região interna dos conectores foi realizada com cola de silicone; 9) microscópio óptico, Carl Zeiss, utilizado na montagem. Este possuiu as funções de suporte mecânico, de observação da região alvo e de controle da microcélula sobre o eletrodo de trabalho (amostra) nas posições X-Y-Z.

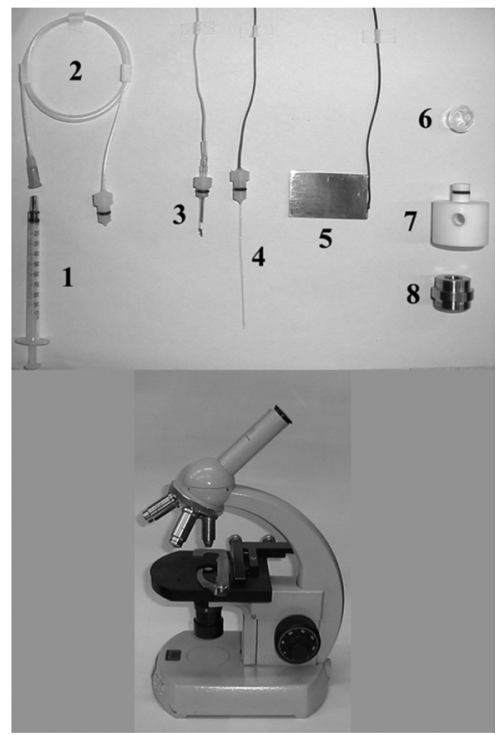

Figura 1. Microcélula com os principais componentes e microscópio utilizado

A Figura 1S, material suplementar, mostra o esquema de conexão dos componentes da microcélula, os canais feitos no interior dos componentes com os números correspondentes aos da Figura 1 e o corpo da microcélula depois de realizadas as conexões.

A ponteira deve terminar em material macio, de modo que possa ser pressionada sobre o eletrodo de trabalho, com o objetivo de minimizar o ingresso de gases atmosféricos, que podem ser eletroativos como $\mathrm{O}_{2}$ ou ocasionar processos indesejados de transporte de massa por convecção, bem como evitar vazamento de solução. Além disso, a ponteira tem a função de evitar o excesso de pressão sobre a amostra que poderia causar microdeformações e também danificar o capilar da microcélula. Para essa função uma ponteira de silicone foi coloca na extremidade inferior do capilar da microcélula.

A Figura 2 mostra a montagem final da microcélula, que ocupa a posição de uma das lentes objetivas do microscópio. Para a observação da região de estudo utilizaram-se lentes de 30x e 100x de magnificação. $\mathrm{O}$ conjunto de lentes era girado posicionando-se uma das lentes sobre a amostra. Após ajustar o foco e com o auxílio da platina do microscópio que produz movimentos no sentido dos eixos $\mathrm{X}-\mathrm{Y}$, girava-se o conjunto das objetivas para posicionar a microcélula sobre amostra na região desejada, justamente no ponto determinado com a lente objetiva. O carrossel do conjunto de lentes mostrou-se adequado para permitir o posicionamento da microcélula sobre a amostra com considerável precisão e exatidão. Após o ajuste da posição da microcélula no ponto de ensaio, ajustava-se o êmbolo da seringa para acertar o menisco de eletrólito na ponteira da microcélula, que era colocada em contato com a amostra. Na sequência, essa ponteira era posicionada sobre a superfície da amostra com auxílio do sistema micrométrico de ajuste de foco no microscópio, que produz um deslocamento no eixo Z. Depois de realizado o primeiro ensaio não era necessário preparar novamente a superfície do eletrodo, pois as demais regiões da amostra não eram alteradas pelo ensaio e se mostravam como áreas virgens. $\mathrm{O}$ ajuste em $\mathrm{Z}$, em outras regiões da amostra, era realizado simplesmente pela observação da graduação no sistema micrométrico para ajuste de foco, já que os eletrodos de trabalho eram pequenas chapas planas; isso também ajudava a evitar uma pressão exacerbada sobre a amostra, que poderia danificar a microcélula e/ou a própria amostra.

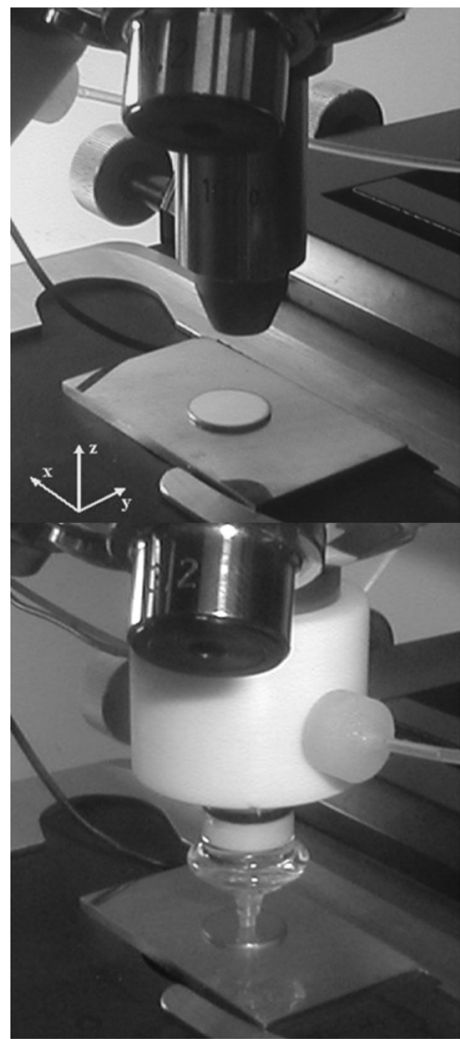

Figura 2. Montagem mostrando a microcélula e microscópio óptico

O diâmetro da extremidade inferior da ponteira foi definido pelo diâmetro de um fio de cobre que foi colocado juntamente com cola de silicone, tendo a função de uma espécie de forma. Para obter a ponteira capilar o fio era removido pela sua dissolução em ácido nítrico concentrado. A dissolução do fio deixa a extremidade da ponteira com um pequeno cilindro de silicone que facilita o ajuste da ponteira sobre a superfície da amostra, evita vazamento de eletrólito e minimiza a aeração diferencial. Como o diâmetro da extremidade inferior da ponteira é determinado pelo diâmetro do fio foi possível variar bastante a área da amostra a ser estudada. Foram obtidos fios com diâmetros entre 20 e $600 \mu \mathrm{m}$, o que permitiu analisar regiões da amostra com área definida por esses diâmetros. A obtenção de fios de pequeno diâmetro foi conseguida por meio de sequências de eletropolimento. ${ }^{26}$

Uma segunda microcélula, mostrada na Figura 3, também foi desenvolvida e alguns aprimoramentos foram realizados. As principais modificações foram: 1) o corpo da célula passou a ser construído de acrílico, devido à possibilidade de usinagem e fabricação de peças com dimensões mais precisas e reprodutíveis quando comparadas às de vidro; 2) a ponteira foi substituída por fibra ótica oca de quartzo. Essa substituição possibilitou obter diâmetros internos menores que $20 \mu \mathrm{m}$ e com boa resistência mecânica. Caso ocorresse um dano no capilar, ou outro diâmetro de capilar fosse necessário, o novo sistema 
de adaptação permitiu uma maior facilidade em sua substituição. Outra vantagem dessa montagem é que dificilmente se rompe o capilar, pois, ao ser pressionado em excesso sobre a amostra, se descoloca no sentido vertical. As fibras óticas foram obtidas por meio de tecnologias desenvolvidas no próprio Instituto de Química; 3) dessa vez uma mesa com coordenadas X-Y-Z, construída na Microtube (Araraquara-SP) foi utilizada para deslocamento da célula. A mesa foi confeccionada com três parafusos micrométricos com a menor graduação produzindo um deslocamento de $5 \mu \mathrm{m}$; 4) também foram utilizadas duas lupas conectadas a um computador. As lupas possibilitaram visualização em tempo real com aumento de até 300x. Uma das lupas foi posicionada na posição horizontal e teve como função facilitar o processo de aproximação da ponteira sobre a superfície da amostra. Outra lupa posicionada na posição vertical também foi utilizada e teve como função facilitar a visualização da região alvo de análise, antes e após o experimento.

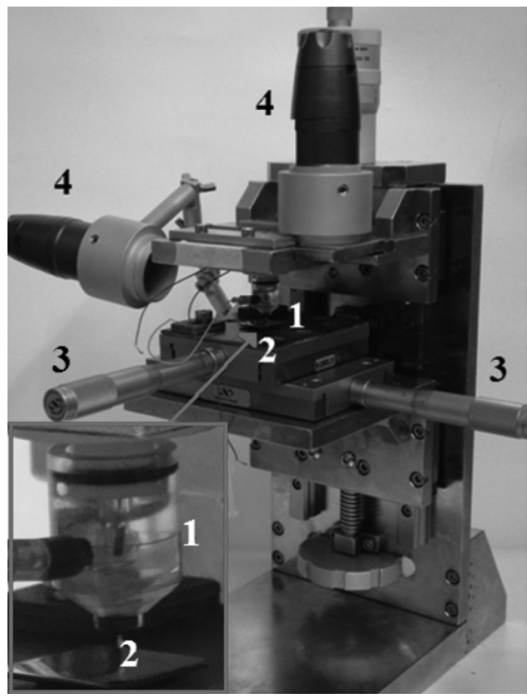

Figura 3. Microcélula aprimorada para estudos localizados e sua montagem sobre uma mesa coordenada $X-Y-Z$

\section{Equipamentos para medidas eletroquímicas}

Para as medidas eletroquímicas foram utilizados um potenciostato da Microquímica MQPG 01 (voltametria cíclica com eletrodo da liga de $\mathrm{Cu}-\mathrm{Al}-\mathrm{Zn}$ ) e as demais medidas foram feitas num potenciostato Gamry Instruments, FAS2 Fentostat, ambos dispostos em gaiola de Faraday e interfaceados com microcomputador. A célula eletroquímica também era colocada dentro da gaiola de Faraday.

\section{RESULTADOS E DISCUSSÃO}

A demarcação e consequente medida da área geométrica onde o experimento foi realizado nem sempre é de fácil execução, uma vez que sua visualização pode ser mais ou menos difícil. A fim de propiciar a medida geométrica da área, diversos experimentos foram realizados utilizando como eletrólito uma solução de $\mathrm{NaCl} 3,5 \% \mathrm{~m} / \mathrm{v}$ sobre um disco de cobre. Dessa forma, aplicou-se uma varredura de potencial $\left(20 \mathrm{mV} \mathrm{s}^{-1}\right)$ entre 0,1 e $0,8 \mathrm{~V}\left(\mathrm{Ag}|\mathrm{AgCl}| \mathrm{Cl}^{-} 3 \mathrm{~mol} \mathrm{~L}^{-1}\right)$. Essas condições proporcionam a oxidação do cobre levando à formação de $\mathrm{CuCl}$ na forma de pirâmides de base triangular e de coloração laranja. ${ }^{27} \mathrm{~A}$ Figura $2 \mathrm{~S}$, material suplementar, mostra micrografias da superfície do cobre após esses experimentos. Foi possível verificar áreas com considerável reprodutibilidade, nítida demarcação e sem vazamentos. O valor médio do diâmetro delimitado pela ponteira utilizada foi de
$608 \mu \mathrm{m}$. Nesses experimentos utilizou-se uma ponteira de $608 \mu \mathrm{m}$, pois se apresentou com um diâmetro adequado ao estudo de cada grão separadamente.

A fim de avaliar o desempenho eletroquímico da microcélula foi utilizado um sistema cujo comportamento eletroquímico é conhecido. ${ }^{28}$ Assim foram obtidos, sobre uma amostra plana de carbono vítreo, voltamogramas cíclicos em diferentes velocidades de varredura de potencial de uma solução equimolar $4 \times 10^{-3} \mathrm{~mol} \mathrm{~L}^{-1}$ de ferricianeto/ ferrocianeto de potássio preparada em $\mathrm{H}_{2} \mathrm{SO}_{4} 0,1 \mathrm{~mol} \mathrm{~L}^{-1}$. A Figura 4 exibe os perfis I-E obtidos com a microcélula $\left(\mathrm{A}_{\text {geom }}=3,1 \times 10^{-4} \mathrm{~cm}^{2}\right)$ e com uma célula convencional $\left(\mathrm{A}_{\text {geom }}=7,1 \times 10^{-2} \mathrm{~cm}^{2}\right)$.
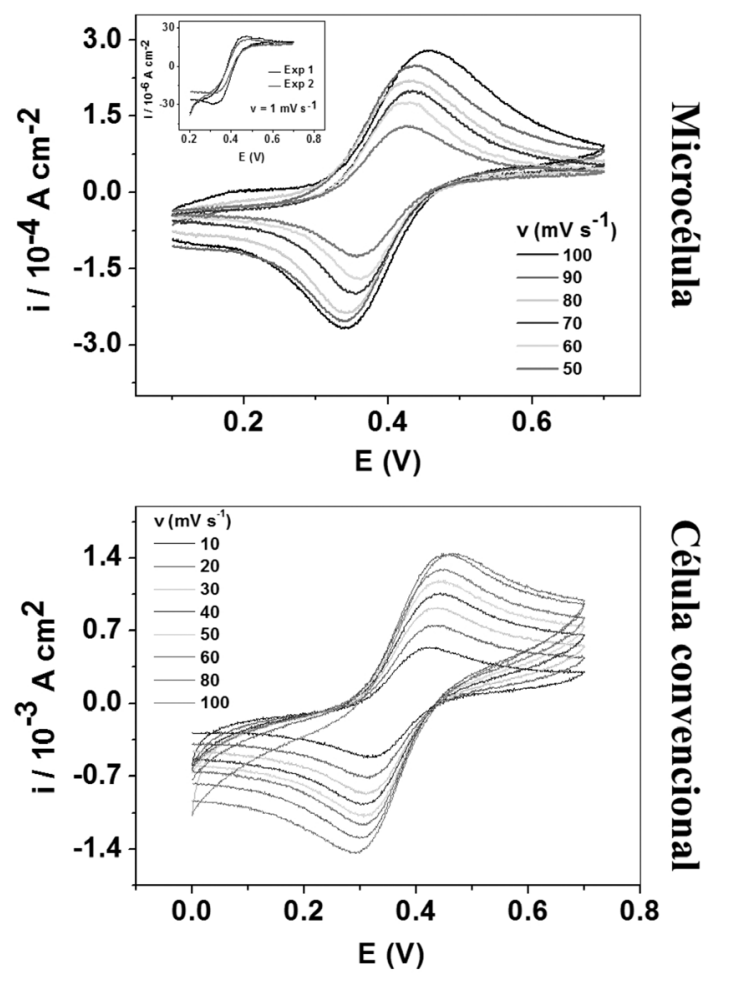

Figura 4. Voltamogramas cíclicos obtidos para carbono vítreo com diferentes velocidades de varredura de potencial em solução contendo $4 \times 10^{-3} \mathrm{~mol} \mathrm{~L}^{-1}$ $\mathrm{Fe}(\mathrm{CN})_{6}^{3-14-} \mathrm{em}_{2} \mathrm{SO}_{4} 0,1 \mathrm{~mol} \mathrm{~L}^{-1}$ para microcélula e célula convencional ${ }^{28}$

Os voltamogramas para a microcélula exibiram efeitos desprezíveis de queda ôhmica, que se caracterizam pelo aumento do coeficiente angular da linha de base dos voltamogramas, e contribuem para o distanciamento entre os potenciais dos picos anódico e catódico. Para a velocidade de varredura de potencial de $50 \mathrm{mV}$ $\mathrm{s}^{-1}$ foi observado um $\Delta \mathrm{Ep}$ de $0,068 \mathrm{~V}$. Os valores de $\Delta$ Ep exibiram um ligeiro aumento com o aumento da velocidade de varredura de potencial. Foi possível por meio da Equação de Randles-Sevcik ${ }^{29}$ calcular os valores dos coeficientes de difusão para a microcélula (processo catódico $\mathrm{D}=4,4 \times 10^{-7} \mathrm{~cm}^{2} \mathrm{~s}^{-1}$ e anódico $\mathrm{D}=2,8 \times 10^{-7}$ $\mathrm{cm}^{2} \mathrm{~s}^{-1}$ ) assim como para a célula convencional (processo catódico $\mathrm{D}=2,7 \times 10^{-6} \mathrm{~cm}^{2} \mathrm{~s}^{-1}$ e anódico $\mathrm{D}=3,2 \times 10^{-6} \mathrm{~cm}^{2} \mathrm{~s}^{-1}$ ), indicando valores relativamente próximos para ambas as células eletroquímicas. Em velocidades de varreduras menores como a $1 \mathrm{mV} \mathrm{s}^{-1}$, detalhe na Figura 4 da microcélula, foi observado que a resposta tende à de um microeletrodo, ou seja, se aproxima de uma curva I-E do tipo sigmoide com pequena histerese. Este comportamento não é esperado para uma microcélula, uma vez que não há possibilidade de difusão radial. Tal comportamento indica um desvio do esperado para difusão linear semi-infinita, podendo ser causado pela baixa velocidade de varredura de potencial, que estende o tempo de eletró- 
lise e resulta não válida a suposição de difusão linear semi-infinita. Esse desvio do comportamento pode ser observado também com eletrodos de tamanho convencional, por exemplo, o voltamograma cíclico (não mostrado neste trabalho) do ferrocianeto de potássio sobre um eletrodo de grafite de $3 \mathrm{~mm}$ de diâmetro forneceu uma curva I-E sigmoide quando foi utilizada uma velocidade de varredura de $10 \mu \mathrm{V} \mathrm{s}^{-1}$. O desvio da resposta esperada para uma difusão linear semi-infinita é fortemente dependente da velocidade de varredura de potencial e do diâmetro do eletrodo se for um plano. Assim, é provável que a resposta da microcélula na velocidade de varredura mais baixa (1 mV s${ }^{-1}$, Figura 4) para a solução de ferro-ferricianeto seja influenciada por uma contribuição outra que unicamente a difusão linear semi-infinita.

A possibilidade de ser empregada a técnica de espectroscopia de impedância eletroquímica na microcélula também foi avaliada. A Figura 3S, material suplementar, exibe o gráfico no plano complexo (Nyquist) para uma solução equimolar $1 \times 10^{-3} \mathrm{~mol} \mathrm{~L}^{-1} \mathrm{de}$ ferricianeto/ferrocianeto de potássio em $\mathrm{KCl} 0,5 \mathrm{~mol} \mathrm{~L}^{-1}\left(\mathrm{~A}_{\text {geom }}=\right.$ $3,1 \times 10^{-4} \mathrm{~cm}^{2}$ ).

O diagrama no plano complexo mostra um semicírculo em alta frequência seguido de uma reta em baixas frequências até $0,2 \mathrm{~Hz}$. A resposta em alta frequência corresponde ao processo de transferência de carga (oxidação e redução do par redox), enquanto que em baixas frequências tem-se o controle por difusão, ou seja, descrito pela impedância de Warburg. ${ }^{23}$ Esse perfil é semelhante ao encontrado na literatura ${ }^{23}$ para células convencionais e comprova a possibilidade da utilização da microcélula para estudos de espectroscopia de impedância eletroquímica.

A microcélula foi aplicada ao estudo de ligas policristalinas de $\mathrm{Cu}-16 \% \mathrm{Zn}-8 \% \mathrm{Al}$ de fase $\beta$, conforme mostrado na Figura 5. Foram realizados estudos voltamétricos para diferentes grãos entre potenciais que levam à formação de espécies de $\mathrm{Cu}_{2} \mathrm{O}$ até potenciais que levam à redução de espécies de $\mathrm{Cu}(\mathrm{I})$. Verificou-se que cada grão responde de forma diferente, tanto para os potencias de pico de oxidação, pois alguns necessitam de maiores potenciais para iniciar esse processo, como para a corrente anódica, pois alguns exibiram uma corrente de oxidação bem superior aos demais. Diferenças significativas também foram encontradas no pico catódico referente à redução de espécies de $\mathrm{Cu}(\mathrm{I})$. Esses resultados mostram que grãos cujas orientações estão mais distantes dos planos de baixo índice de Miller exibem uma superfície mais ativa, talvez relacionada ao maior número de degraus atômicos.

A Figura 4S, material suplementar, mostra outra aplicação da microcélula; a mesma foi utilizada para obtenção de curvas de polarização em biodiesel de soja obtido via rota metílica, um meio altamente resistivo, sem adição intencional de eletrólito de suporte.

Como as curvas de polarização são apenas ilustrativas das possibilidades de uso do dispositivo descrito neste trabalho, não foi feita a correção de queda ôhmica. Na célula utilizada, o eletrodo de referência foi um fio de óxidos de tungstênio ${ }^{30}$ em curto circuito com o eletrodo auxiliar da microcélula. Pode-se observar que as curvas de polarização para o aço carbono (de tanques de armazenamento) em biodiesel não apresentam ruído e as correntes de corrosão estimadas foram, respectivamente, $5 \times 10^{-10} \mathrm{~A} \mathrm{~cm}^{-2}\left(10 \mathrm{mV} \mathrm{s}^{-1}\right)$ e $2,5 \times 10^{-9} \mathrm{~A}$ $\mathrm{cm}^{-2}\left(1 \mathrm{mV} \mathrm{s}^{-1}\right)$ com potencial de corrosão ao redor de $-0,145 \mathrm{~V}$ (10 $\left.\mathrm{mV} \mathrm{s}^{-1}\right)$ e $-0,02 \mathrm{~V}\left(1 \mathrm{mV} \mathrm{s}^{-1}\right)$ medidos versus um fio de tungstênio recoberto com óxidos de tungstênio.

A comparação entre resultados obtidos com uma célula de um sistema comercial e a descrita neste trabalho encontra-se descrita na literatura ${ }^{31}$ para o aço CFF em solução $0,6 \mathrm{~mol} \mathrm{~L}^{-1} \mathrm{NaCl}$, onde é possível verificar a coerência dos resultados, que os mesmos são comparáveis como também reprodutíveis. Além disso, a Figura 5S, material suplementar, mostra uma curva de polarização obtida para
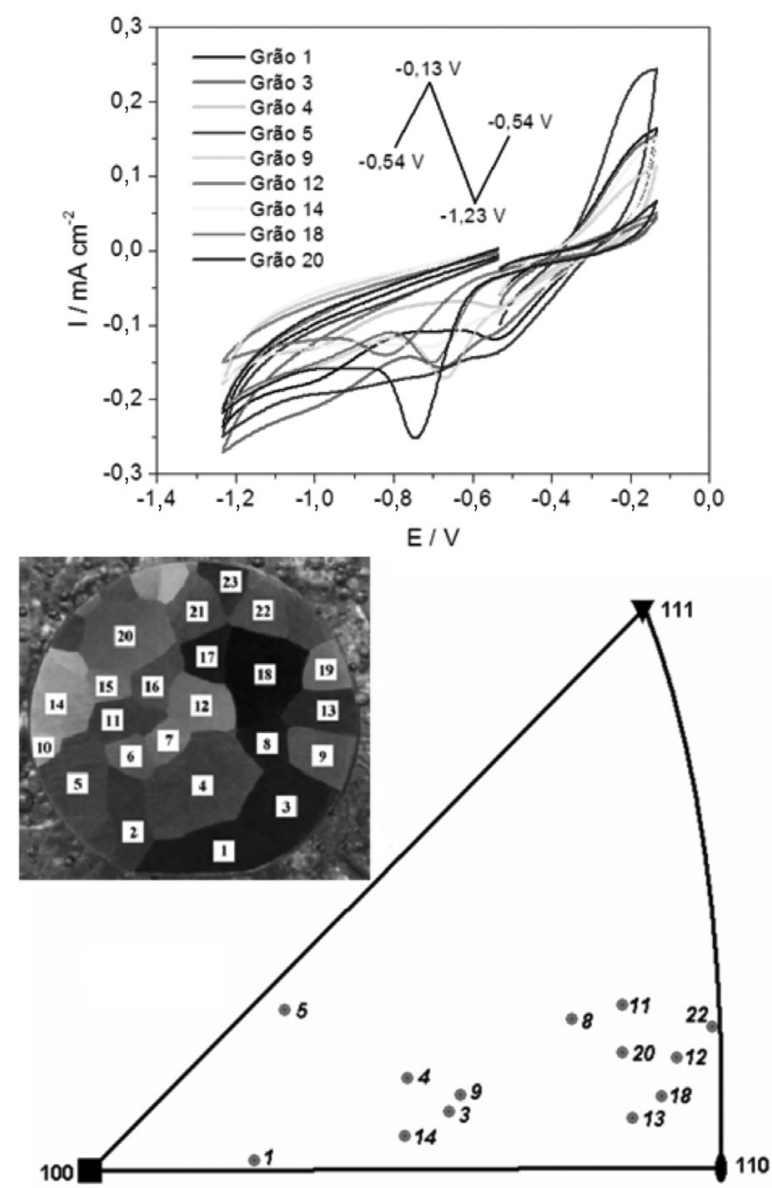

Figura 5. Resultados eletroquímicos obtidos para diversos grãos da liga policristalina de $\mathrm{Cu}-16 \% \mathrm{Zn}-8 \% \mathrm{Al}$ de fase $\beta$ e suas respectivas orientações no triângulo fundamental ${ }^{4}$

o aço SAE 1045 (F114) em solução $0,6 \mathrm{~mol} \mathrm{~L}^{-1} \mathrm{NaCl}$ e $0,2 \mathrm{mV} \mathrm{s}^{-1}$ com a microcélula aqui descrita, que é comparável às obtidas com uma microcélula comercial, num estudo sobre o mesmo material e nas mesmas condiçoes. ${ }^{13} \mathrm{~A}$ comparação deve ser feita com as curvas da Figura 6 da ref. 13. Pode-se observar que ambas figuras mostram valores concordantes, considerando o fato de se trabalhar com uma microcélula que mede regiões muito pequenas da amostra, que por sua vez não apresenta a homogeneidade de um material puro. Assim, considera-se que a microcélula construída em nosso laboratório produz resultados similares à comercial. Essas medidas bem como os dados obtidos para o par $\left[\mathrm{Fe}(\mathrm{CN})_{6}\right]^{3-/ 4-}$ por voltametria cíclica e espectroscopia de impedância eletroquímica com a microcélula e com a célula de tamanho convencional validam a microcélula descrita no presente trabalho.

\section{CONCLUSÕES}

A microcélula eletroquímica é um novo e poderoso conceito para investigações de microrregiões. $\mathrm{O}$ dispositivo desenvolvido se mostrou útil para inúmeros estudos eletroquímicos em regiões da amostra delimitadas por um microcapilar. Os materiais empregados na construção da microcélula são de baixo custo e podem ser encontrados na maioria dos laboratórios. O controle do dispositivo pode ainda ser totalmente automatizado e conectado a um computador. Possui grande potencial de utilização em inúmeras outras aplicações, com pequeno consumo de reagentes e obtenção de resultados de boa qualidade. 


\section{MATERIAL SUPLEMENTAR}

Está disponível em http://quimicanova.sbq.org.br, na forma de arquivo pdf e com acesso livre.

\section{AGRADECIMENTOS}

Ao apoio financeiro da FAPESP (proc. 04/11984-2 e proc. 07/53633-0) e ao CNPq (procs. 305890/2010-7, 576273/2008-2), e aos Srs. F. C. Palachini (pela montagem da mesa X-Y-Z) e S. A. Dametto (pelos serviços de usinagem).

\section{REFERÊNCIAS}

1. Rosatto, S. S.; Cabot, P. L.; Sumodjo, P. T. A.; Benedetti, A. V.; Electrochim. Acta 2001, 46, 1043.

2. Blanco, M.; Barelli, N.; Flor, S. W. A.; Benedetti, A. V.; Quim. Nova 2003, $26,757$.

3. Zambrano, U. C.; Blanco, M.; Barelli, N.; Benedetti, A. V.; Fernandez, J.; Quim. Nova 2008, 31, 154.

4. Barragan, J. T.; Dissertação de Mestrado, Universidade Estadual Paulista Julio de Mesquita Filho, Brasil, 2007.

5. Cullity, B. D.; Elements of X-ray diffraction, $2^{\text {nd }}$ ed., Addison-Wesley Publishing Company Inc: New York, 1978.

6. Schwartz, A. J.; Kumar, M.; Adams, B. L.; Field, D. P.; Electron backscatter diffraction in materials science, $2^{\text {nd }}$ ed., Springer Science: New York, 2009.

7. Park, C. J.; Lohrengel, M. M.; Hamelmann, T.; Pilaski, M.; Kwon, H. S.; Electrochim. Acta 2002, 47, 3395.

8. Schreiber, A.; Schultze, J. W.; Lohrengel, M. M.; Kármán, F.; Kálmán, E.; Electrochim. Acta 2006, 51, 2625.

9. Schreiber, A.; Rosenkranz, C.; Lohrengel, M. M.; Electrochim. Acta 2007, 52, 7738.

10. Park, C.-H.; Kwon, H.-S.; Lohrengel, M. M.; Mater. Sci. Eng. 2004, A372, 180.

11. Hassel, A.W.; Lohrengel, M. M.; Electrochim. Acta 1997, 42, 3327.
12. Pilaski, M.; Hamelmann, T.; Moehring, A.; Lohrengel, M. M.; Electrochim. Acta 2002, 47, 2127.

13. Andreatta, F.; Matesanz, L.; Akita, A. H.; Paussa, L.; Fedrizzi, L.; Fugivara, C. S.; Salazar, J. M. G.; Benedetti, A. V.; Electrochim. Acta 2009, 55, 551.

14. Hamelmann, T.; Lohrengel, M. M.; Electrochim. Acta 2001, 47, 117.

15. Vogel, A.; Schultze, J. W.; Electrochim. Acta 1999, 44, 3751.

16. Lohrengel, M. M.; Kluppel, I.; Rosenkranz, C.; Bettermann, H.; Schultze, J. W.; Electrochim. Acta 2003, 48, 3203.

17. Walther, B.; Schilm, J.; Michaelis, A.; Lohrengel, M. M.; Electrochim. Acta 2007, 52, 7732 .

18. Pilaski, M.; Lohrengel, M. M.; Electrochim. Acta 2003, 48, 1309.

19. Suter, T.; Böhni, H.; Electrochim. Acta 2001, 47, 191.

20. Andreatta, F.; Lohrengel, M. M.; Terryn, H.; Wit, J. H. W. de; Electrochim. Acta 2003, 48, 3239.

21. Klemm, S. O.; Kollender, J. P.; Hassel, A. W.; Corros. Sci. 2011, 53, 1.

22. Suryavanshi, A. P.; Yu, M.-F.; Appl. Phys. Lett. 2006, 88, 083103.

23. Orazem, M. E.; Tribollet, B.; Electrochemical Impedance Spectroscopy, $1^{\text {st }}$ ed., John Wiley \& Sons Inc: New Jersey, 2008.

24. Lohrengel, M. M.; Heiroth, S.; Kluger, K.; Pilaski, M.; Walther, B.; Electrochim. Acta 2006, 51, 1431.

25. Lohrengel, M. M.; Rosenkranz, C.; Klüppel, I.; Moehring, A.; Bettermann, H.; Bossche, B. V.; Deconinck, J.; Electrochim. Acta 2004, 49, 2863.

26. Landolt, D.; Electrochim. Acta 1987, 32, 1.

27. Benedetti, A. V.; Sumodjo, P. T. A.; Nobe, K.; Cabot, P. L.; Proud, W. G.; Electrochim. Acta 1995, 40, 2657.

28. Akita, A. H.; Dissertação de Mestrado, Universidade Estadual Paulista Julio de Mesquita Filho, Brasil, 2009.

29. Bard, A. J.; Faulkner, L. R.; Electrochemical Methods, Fundamentals and Applications, $2^{\text {nd }}$ ed., Wiley: New York, 1980.

30. Tada, E.; Sugawara, W.; Kaneko, H.; Electrochim. Acta 2004, 49, 1019.

31. Andreatta, F.; Paussa, L; Akita, A. H.; Fugivara, C. S.; Benedetti, A. V.; Fedrizzi, F.; Proceedings of the European Corrosion Congress - EUROCORR-2010, Moscow, Russia, 2010. 


\section{DESENVOLVIMENTO DE MICROCÉLULA ELETROQUÍMICA PARA ESTUDOS DE MICRORREGIÕES}

Adriano Heleno Akita, José Tiago Claudino Barragan, Cecílio Sadao Fugivara e Assis Vicente Benedetti*

Departamento de Físico-Química, Instituto de Química, Universidade Estadual Paulista Julio Mesquita Filho, CP 355, 14801-970 Araraquara - SP, Brasil

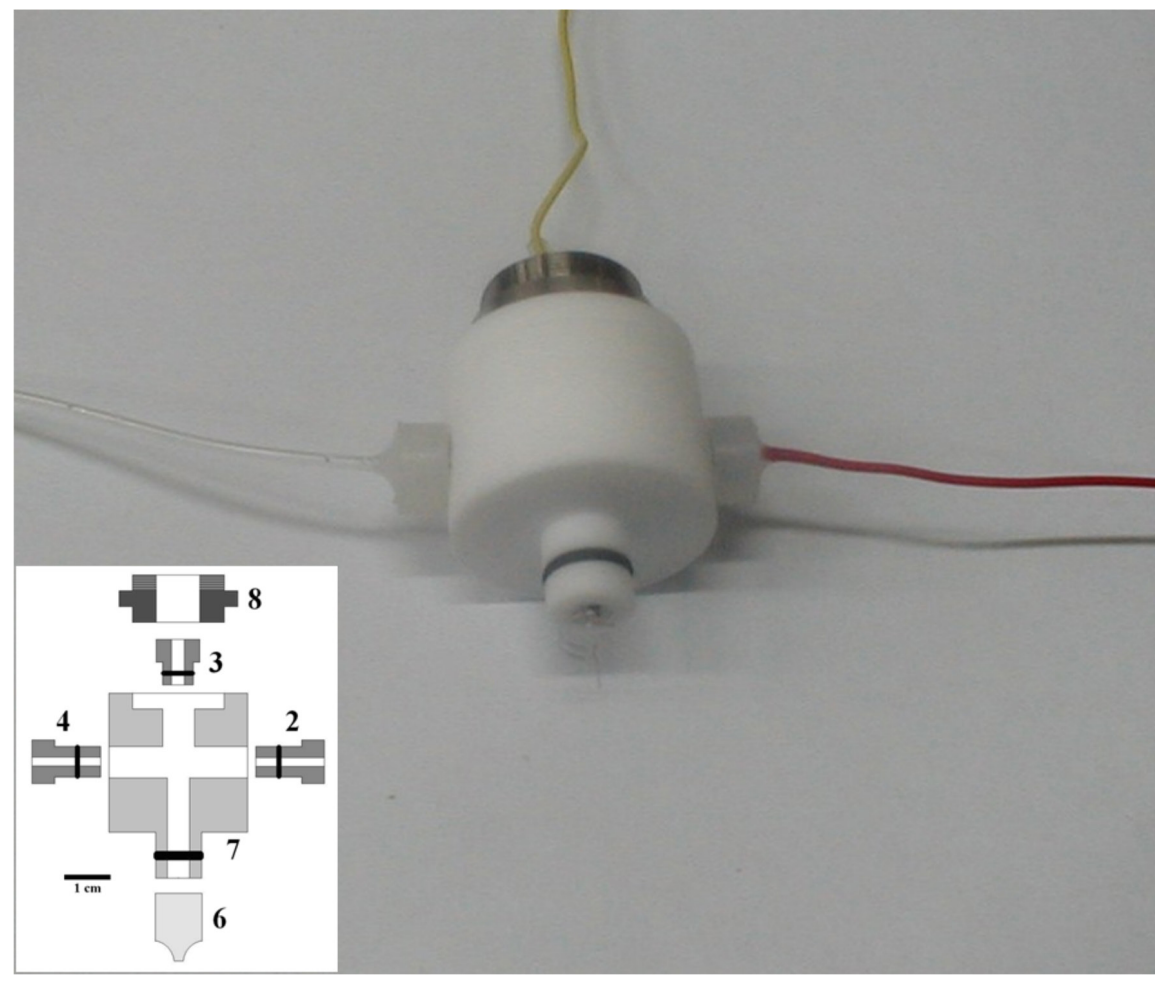

Figura 1S. Montagem da microcélula com o esquema de conexão dos componentes e a microcélula após a conexão

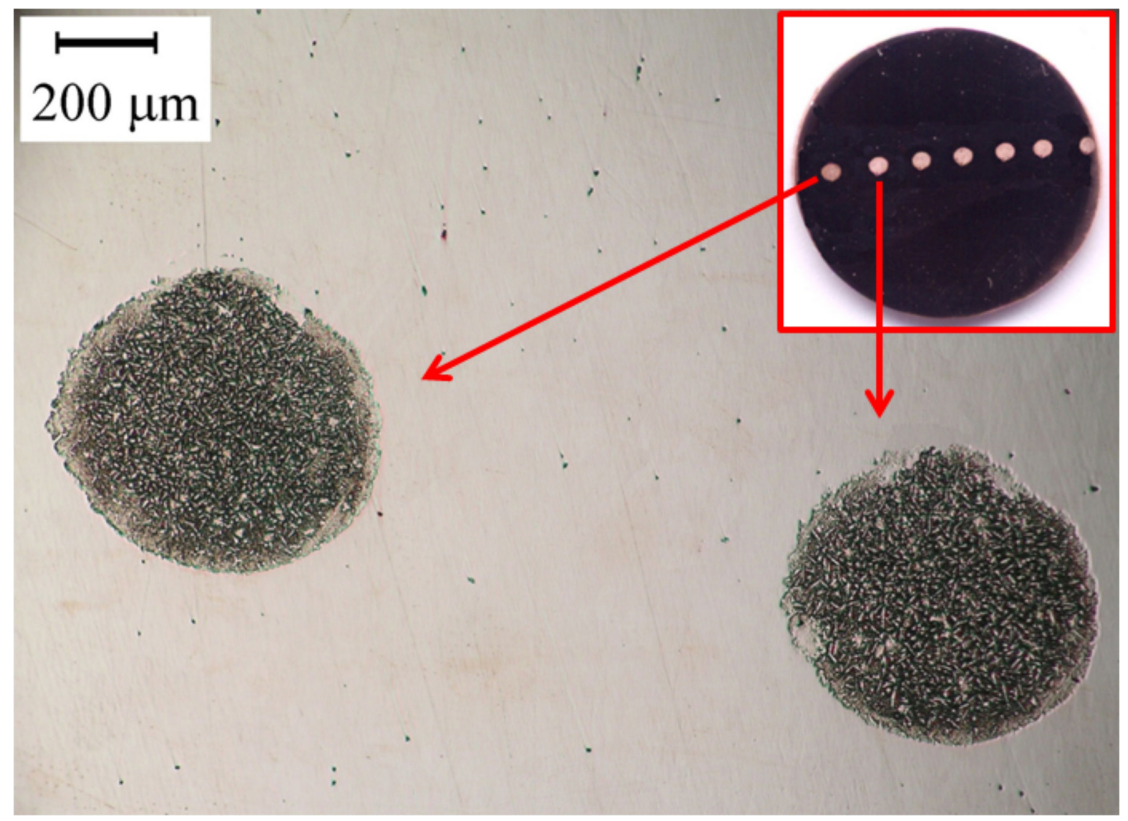

Figura 2S. Micrografias ópticas mostrando a área delimitada pela ponteira ${ }^{4}$ 


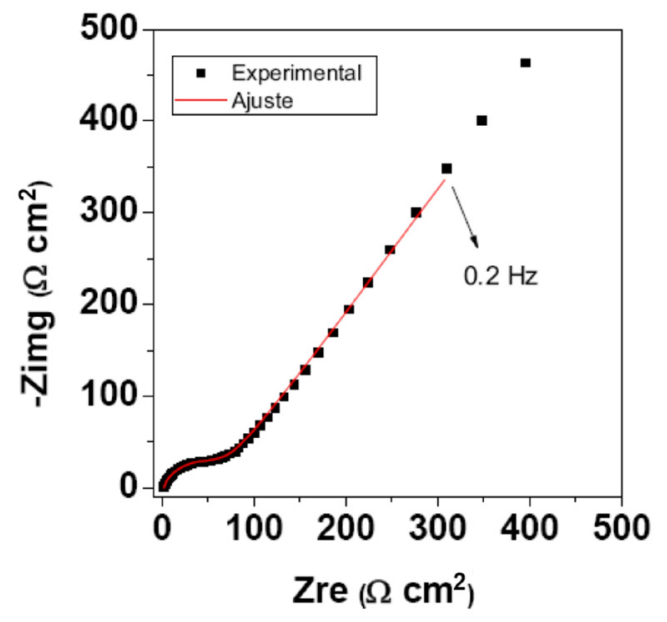

Figura 3S. Diagrama no plano complexo da microcélula para eletrodo de platina em solução equimolar $1 \times 10^{-3} \mathrm{~mol} \mathrm{~L}^{-1}$ de ferricianeto/ferrocianeto de potássio preparada em $\mathrm{KCl}$ 0,5 $\mathrm{mol} \mathrm{L}^{-1}$. Amplitude $10 \mathrm{mV}$ (rms) e 10 pontos/ década de frequência ${ }^{28}$

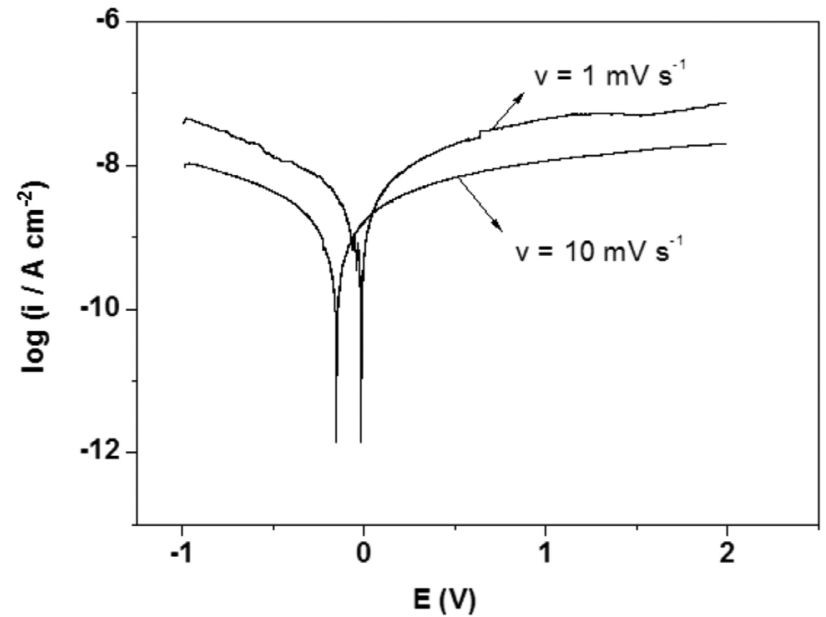

Figura 4S. Curvas de polarização para aço carbono obtidas em biodiesel sem adição intencional de eletrólito de suporte e sem correção de queda ôhmica

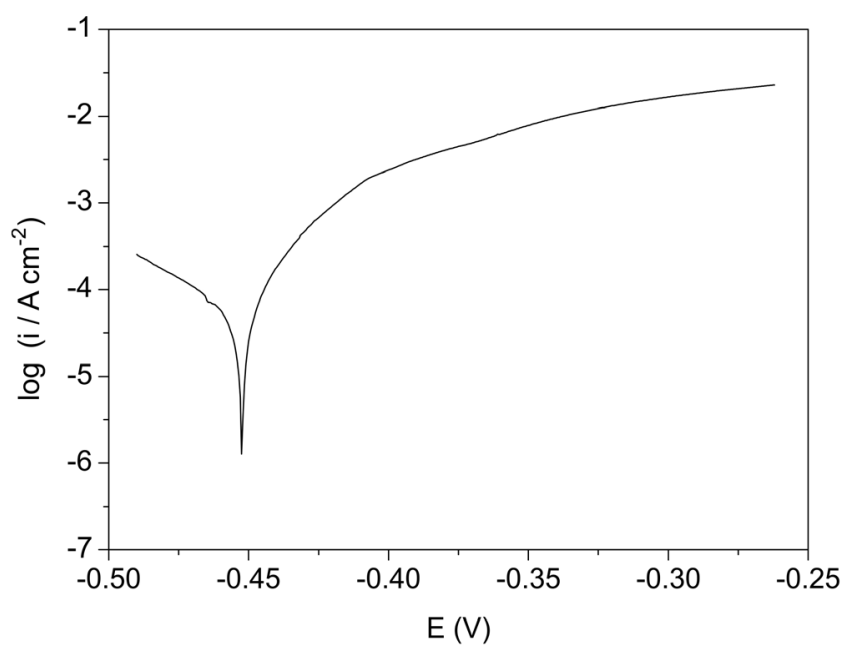

Figura 5S. Curva de polarização do aço SAE 1045 obtida em NaCl 0,6 mol $L^{-1}$ com velocidade varredura do potencial de $0,2 \mathrm{mV} \mathrm{s}^{-1}$ a $25^{\circ} \mathrm{C}$ 